\title{
MODIFICAÇÕES DO MICROCLIMA E REGIME HIDROLÓGICO DEVIDO AO DESMATAMENTO NAAMAZÔNIA: ESTUDO DE UM CASO EM RONDÔNIA (RO), BRASIL.
}

\section{Francisco Sérgio Maia ALVES, Gilberto FISCH, Íria Fernandes VENDRAME}

RESUMO - As mudanças no microclima e no balanço hídrico devido ao desmatamento na Amazônia (região de Ji-Paraná-RO) foram estudadas com dados meteorológicos coletados de janeiro/ 92 até outubro/93, em sitios experimentais de floresta tropical e de pastagem. Observou-se que a troca de vegetação (desmatamento) reduz a precipitação total em $10 \%$, diminui a evapotranspiração real de $24 \%$ e também apresenta uma maior amplitude térmica da temperatura do ar de $1,6^{\circ} \mathrm{C}$. A análise do balanço hidrico mostra claramente que a floresta tropical consegue extrair mais água do que o sítio de pastagem durante a estação seca, embora os dois sitios possuam comportamentos similares durante a estação chuvosa.

Palavras-Chaves: Microclima, Balanço Hidrico, Desmatamento, Amazônia

Microclimate and Hidrology Modifications Due to the Deforestation in the Amazônia: a Case Study in Rondônia State (RO), Brazil.

ABSTRACT - The microclimate and hydrology changes due to the deforestation in the Amazon (Ji-Paraná region-RO) have been studied using micromet data from January/92 until December $/ 93$ collected at the tropical forest and pasture sites. It has been observed that the landuse change can reduce the rainfall by $10 \%$, decrease the actual evapotranspiration by $24 \%$ and an increase of the daily air temperature range (by $1.6^{\circ} \mathrm{C}$ ). Also, the water budget clearly shows that the tropical forest can extract more water than the pasture during the dry season, although they have similar trends in the wet season.

Key-words: Microclimate, Water Budget, Deforestation, Amazon region

\section{INTRODUÇÃO}

Nos últimos anos a Amazônia tem sido foco de discussões no mundo inteiro à respeito de sua importância no equilíbrio do ecossistema terrestre e do impacto que a sua completa devastação teria sobre $o$ clima regional e global. Alguns estudos de simulação climática sobre o tema (Nobre et al., 1991; Fisch et al., 1997) indicam que o desmatamento completo da Floresta Amazônica provocaria, na região, um aumento de 0,6 a $2,0{ }^{\circ} \mathrm{C}$ na temperatura do ar, uma diminuição de 20 a $30 \%$ nas taxas de precipitação e de evapotranspiração e estações secas mais prolongadas.

Em vista disso, é de fundamental importância o entendimento dos complexos mecanismos de formação do clima da região e de como as diversas variáveis envolvidas no processo se modificam com a alteração da superfície vegetada. A substituição de floresta por pastagem modifica as interações entre a vegetação e a atmosfera. Se grandes extensões forem desmatadas, o clima da região será, portanto, influenciado.

O objetivo do presente estudo é fazer uma análise comparativa dos elementos climáticos registrados em áreas desmatadas (pastagem) e de floresta tropical, afim de compreender de que forma o desmatamento afetam o ciclo hidrológico (em termos da precipitação e evapotranspiração ). Ao

\footnotetext{
Centro Técnico Aeroespacial (CTA), São José dos Campos, 12228-904, SP
} 
final é feita uma estimativa preliminar do balanço hídrico (considerando os componentes de precipitação, evapotranspiração e água armazenada no solo) para os sitios de floresta e de pastagem do Projeto ABRACOS, na região de Ji-Paraná (RO).

\section{MATERIAL E MÉTODOS}

\section{Instrumentação}

No topo de torres de alumínio foram instaladas estações meteorológicas automáticas que medem fluxo de radiação solar incidente e refletida, saldo de radiação, temperatura e umidade especifica do ar, precipitação, velocidade e direção do vento e fluxo de calor conduzido ao solo. Para se medir a radiação solar incidente e refletida foram utilizados piranômetros CM-5 da Kipp \& Zonen (Delft, The Netherlands). As medições do saldo de radiação foram feitas por um saldo radiomêtro $Q^{*} 6$ (REBS, Seattle, USA). O fluxo de calor do solo foi medido através de fluxímetros Thornthwaite - modelo 610 (Elmer, New Jersey, USA), os quais foram instalados a uma profundidade de $5 \mathrm{~mm}$. As temperaturas de bulbo seco e úmido foram medidas utilizando-se psicrômetros aspirados, com base em termômetros de resistência de platina $(\mathrm{IH}$, Wallingford. UK), sendo que a precisão das medidas foi de $\pm 0,1{ }^{\circ} \mathrm{C}$. Os valores horários de precipitação foram coletados com pluviômetros do tipo báscula, com resolução de 0,2 mm (Didcot Instrument Company, Abingdom, UK). Os valores de direção e velocidade do vento foram obtidos com anemômetros de conchas (Didcot Instrument Company, Abingdom,
UK), sendo que a precisão das medidas do vento são de $0,5 \mathrm{~m} \cdot \mathrm{s}^{-1}$ para a velocidade e de 1 grau para a direção. As medidas de quantidade de água no solo foram realizadas com sondas de neutrons (Didcot Instrument Company, Abingdom, UK).

\section{Sítios experimentais}

Os dados utilizados foram coletados em Ji-Paraná, localizada no estado de Rondônia, na porção sudoeste da Amazônia. Na área de coleta de dados existe uma região representativa da vegetação nativa de floresta tropical e outra de área desmatada, correspondendo a Reserva Jaru e a fazenda Nossa Senhora da Aparecida, respectivamente. A distância entre estes dois sítios é de aproximadamente $80 \mathrm{~km}$. O período de coleta de dados foi de janeiro de 1992 à outubro de 1993.

\section{Reserva Jaru, Ji-Paraná (RO)}

A Reserva Biológica do Rio Jaru $\left(10^{\circ} 05^{\prime} \mathrm{S}\right.$ e $\left.61^{\circ} 55^{\circ} \mathrm{W}\right)$ é uma reserva florestal de propriedade do Instituto Brasileiro de Meio Ambiente (IBAMA), localizada cerca de $80 \mathrm{~km}$ ao norte de JiParaná e a $120 \mathrm{~m}$ do nível do mar. É caracterizada por uma altura média do dossel de cerca de $33 \mathrm{~m}$. As espécies de árvores mais altas, situadas ao redor da torre, são : Cedrella odorata, Inga sp., Dioclea cf bicolor Bth., Strychnos amazonicus Krukoff, Protium polybotrium e Leonia glycicarpa Ruiz.

\section{Fazenda Nossa Senhora da Aparecida, Ouro Prêto D'Oeste (RO)}

Este sítio $\left(10^{\circ} 45^{\prime} \mathrm{S}\right.$ e $\left.62^{\circ} 21^{\prime} \mathrm{W}\right)$ foi estabelecido em outubro de 1991, numa fazenda de gado $220 \mathrm{~m}$ acima 
do nível do mar e cerca de $50 \mathrm{~km}$ a nordeste de Ji-Paraná. Este sítio foi desmatado cerca de 14 anos atrás e está no centro de uma área deflorestada de aproximadamente $50 \mathrm{~km}$ de raio. A grama (Brachiaria brizantha-A. Rich.) é grumosa e as raízes da cobertura vegetal inicial ainda podem ser vistas. A pastagem foi queimada no mês anterior à da instalação da aparelhagem e, desde então, não sofreu nova queima até o periodo de medições utilizadas no presente trabalho. A estação automática está instalada no topo de uma torre de alumínio de $6 \mathrm{~m}$ de altura.

\section{METODOLOGIA}

\section{Estimativa da evapotranspiração}

A evapotranspiração horária foi calculada através da equação de Penman-Monteith, a saber:

$$
\mathrm{EVT}=\frac{s\left(R_{n}-G-B\right)+\rho C_{p}\left(e_{s}-e_{a}\right) / r_{a}}{s+\Delta\left(1+\frac{r_{s}}{r_{a}}\right)}
$$

onde EVT é a evapotranspiração (W.m-2 ${ }^{-2}$, $R_{n}$ é o saldo de radiação $\left(\mathrm{W} \cdot \mathrm{m}^{-2}\right), G$ é o fluxo de calor conduzido ao solo $\left(\mathrm{W} \cdot \mathrm{m}^{-2}\right)$, $B$ é a variação no armazenamento de energia na biomassa $\left(W \cdot m^{-2}\right), \rho$ é a massa especifica do ar em $\left(\mathrm{kg} \cdot \mathrm{m}^{-3}\right), C_{p}$ é o calor específico do ar à pressão constante em $\left(\mathrm{J}^{\mathrm{kg}}{ }^{-1} \cdot{ }^{\circ} \mathrm{C}^{-1}\right),\left(\mathrm{e}_{\mathrm{s}}-\mathrm{e}_{\mathrm{a}}\right)$ é o défícit de pressão de vapor d'água em $\mathrm{mb} ; s$ é o coeficiente angular da curva que relaciona pressão de saturação do vapor d'água e a temperatura do ar $\left(\mathrm{mb} .{ }^{0} \mathrm{C}^{-1}\right), r_{s}$ é a resistência estomática das folhas $\left(\mathrm{s} . \mathrm{m}^{-1}\right), r_{a}$ é a resistência aerodinâmica do $\operatorname{ar}\left(\mathrm{s} . \mathrm{m}^{-1}\right)$ e $\Delta$ é o parâmetro psicrométrico em $\left(\mathrm{mb} \cdot{ }^{0} \mathrm{C}^{-1}\right)$.

\section{Energia armazenada na biomassa (B)}

Segundo Moore \& Fisch (1986), a variação da energia armazenada na biomassa pode ser estimada a partir de medidas da temperatura da biomassa e da distribuição da biomassa. A variação desta energia armazenada pode ser um componente significativo do balanço de energia a nível horário, quando a quantidade de biomassa é grande (caso das florestas). Porém, nem sempre é possivel obter medidas da temperatura da biomassa, da temperatura do ar do dossel e da umidade. Assim sendo, Moore \& Fisch (1986) propuseram uma parametrização mais simples para o cálculo da energia armazenada pela biomassa, em áreas de floresta tropical, a saber:

$$
B_{i}=16,7 \delta T_{i}+28,0 \delta q_{i}+12,6 \delta T_{i+1}
$$

onde $B_{i}$ é a energia da biomassa armazenada $\left(\mathrm{W} \cdot \mathrm{m}^{-2}\right)$ na hora $i$, ou seja entre a hora $i-1$ e $i, \delta T_{i}$ é a variação apresentada pela temperatura $\left({ }^{\circ} \mathrm{C}\right)$ na hora $i, \delta q_{i}$ é a variação apresentada pela umidade específica $\left(\mathrm{g} \cdot \mathrm{kg}^{-1}\right)$ na hora $i, \delta T_{i+1}$ é a variação apresentada pela temperatura $\left({ }^{\circ} \mathrm{C}\right)$ na hora $i+1$.

\section{Resistências aerodinâmica e estomática}

A água existente no interior da cavidade sub-estomatal das folhas sofre a atuação de uma resistência quando escapa através da abertura estomatal por difusão molecular. A soma da resistência de cada folha é a resistência estomática da vegetação. No cálculo da evapotranspiração, usou-se os resultados obtidos por Wright et al. (1996) para os valores da 
resistência esiomática (Fig. 1) em dias representativos das estações úmida e seca.

A resistência aerodinâmica foi calculada pela expressão:

$$
r_{a}=\frac{33}{V}
$$

onde $r_{\mathrm{a}}$ é a resistência aerodinâmica em $\mathrm{s} . \mathrm{m}^{-1} ; \mathrm{e} V$ é a velocidade do vento em $\mathrm{m} . \mathrm{s}$ '. Esta expressão foi obtida empiricamente por Shuttleworth et al., (1984) para a área de floresta tropical.

\section{Água acumulada no solo}

A quantidade de água no solo foi calculada com valores médios da umidade volumétrica do solo, valores estes medidos próximos às estações automáticas por sondas de neutrons. Para o sítio experimental localizado na Reserva Jaru, havia oito tubos de medição de umidade, enquanto na Fazenda Nossa Senhora Aparecida havia apenas seis tubos. Os valores apresentados correspondem a média destes tubos, visando melhorar a representatividade espacial. As medições iniciaram-se em outubro de 1991, na Reserva Jaru, e em novembro de 1991, na Fazenda Nossa Senhora Aparecida. Os dados utilizados foram de janeiro de 1992 até dezembro de 1993, em ambos os sítios, sendo que a coleta de dados foi aproximadamente em intervalo semanal.

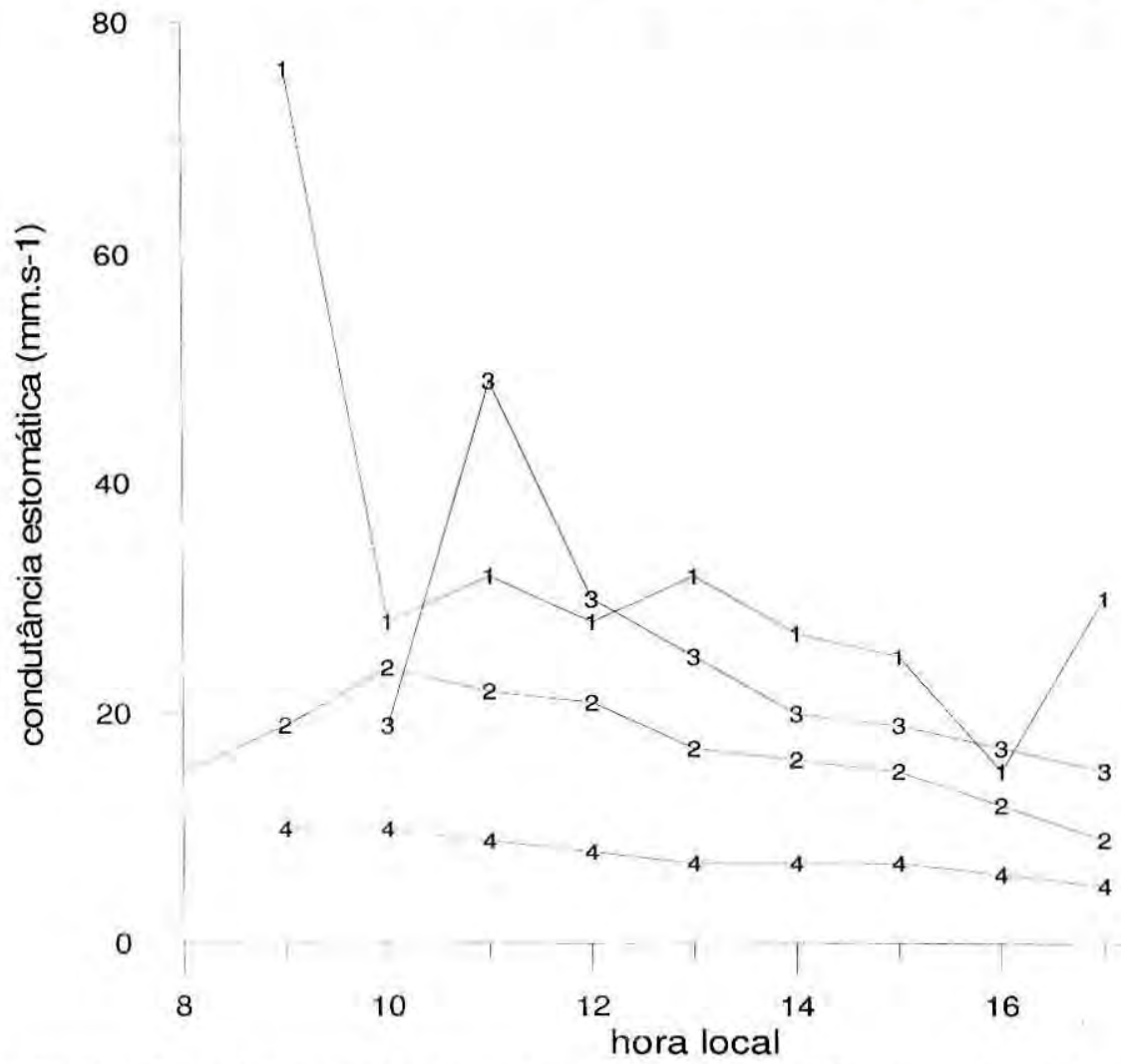

Figura 1. Condutancia estomática para as áreas de floresta tropical ( $1=$ estação chuvosa e $3=$ estação seca) e pastagem ( $2=$ estação chuvosa e $4=$ estação seca). (Extraido de Wright et al:; 1996). 


\section{Balanço Hídrico}

O balanço hídrico ( $\mathrm{mm}$ ) foi calculado como composto, em intervalo de tempo semanal, do total de água precipitado, do total evapotranspirado e da variação da quantidade de água no solo, ou seja:

$$
\mathrm{P}=\mathrm{EVT}+\mathrm{ES}+\mathrm{DP}+\Delta \mathrm{S}
$$

onde P é a precipitação; EVT é a evapotranspiração; ES é o escoamento superficial; DP é a drenagem profunda e $\Delta S$ é a variação da quantidade de água no solo $\left(\Delta \mathrm{S}=\mathrm{S}_{\mathrm{i}+1}-\mathrm{S}_{\mathrm{i}}\right)$, sendo $\mathrm{S}_{\mathrm{i}}$ é a quantidade de água no instante $i$. Todos estes componentes estão em mm. Nestas análises agrupou-se os dois termos (ES e DP) não medidos na equação (4) em um único termo denominado de resíduo $(\mathrm{R})$.

\section{RESULTADOS}

\section{Ciclo Sazonal}

Ao efetuar-se a análise comparativa, procurou-se assegurar que os sítios de floresta e pastagem possuissem os mesmos números de dias de dados. Dessa forma foram eliminados os erros relativos a números diferentes de dados disponíveis para cada variável. A análise do comportamento sazonal das principais variáveis (fluxos de radiação, temperatura e umidade específica do ar, velocidade do vento, precipitação e evapotranspiração) foi baseada no valores característicos mensais durante o período de janeiro de 1992 até outubro de 1993.

\section{Radiação solar global}

Observa-se, na Figura 2, que a radiação solar global na floresta foi quase sempre maior que a medida na pastagem. No período total de análise, a média da radiação solar global integrada ao longo do dia na floresta foi $17,4 \mathrm{MJ} \cdot \mathrm{m}^{-2} \cdot \mathrm{dia}^{-1}$, enquanto na pastagem este valor foi $16,8 \mathrm{MJ} . \mathrm{m}$ ${ }^{2}, \mathrm{dia}^{-1}$. No período seco (trimestre junho-julho-agosto), a radiação solar global média foi $18,4 \mathrm{MJ} \cdot \mathrm{m}^{-2} \cdot \mathrm{dia}^{-1}$ na floresta e $17,1 \mathrm{MJ} \cdot \mathrm{m}^{-2} \cdot \mathrm{dia}^{-1}$ na pastagem. No período chuvoso (janeiro-fevereiro-março) a radiação solar global média foi $16,3 \mathrm{MJ}^{-2}$.dia ' na floresta e também na pastagem. Constatou-se, portanto, que entre o período seco e o chuvoso houve uma redução do valor da radiação solar global. Este fato está relacionado com uma maior nebulosidade na estação chuvosa. O maior valor de radiação solar global na floresta durante a estação seca deve-se a menor presença de aerossóis, devido ao efeito de queimada (Feitosa et al., 1998). Em relação ao saldo de radiação, também apresentado na Figura 2, foi observado que o saldo de radiação total diário foi quase sempre maior na floresta, devido ao menor albedo. Em média, o saldo da radiação total diảrio assumiu, no período todo, o valor de $11,5 \mathrm{MJ} \cdot \mathrm{m}^{-2} \cdot \mathrm{dia}^{-1}$ na floresta e 9,8 MJ.m.-2.dia ${ }^{-1}$ na pastagem. No período seco, o saldo de radiação total diário médio foi $11,5 \mathrm{MJ} \cdot \mathrm{m}^{-2} \cdot \mathrm{dia}^{-1}$ na floresta e 9,3 MJ.m. ${ }^{-2}$.dia ${ }^{-1}$ na pastagem. No período chuvoso, o saldo de radiação total diário médio foi $11,5 \mathrm{MJ} \cdot \mathrm{m}^{-2}$. dia ${ }^{-1}$ na floresta e $10,3{\mathrm{MJ} . \mathrm{m}^{-2} \text {.dia }}^{-1}$ na pastagem.

Verificou-se que não houve uma variação no valor do saldo de radiação total diário médio entre as estações seca e chuvosa, no sítio de floresta. Embora a incidência solar tenha diminuído, em 


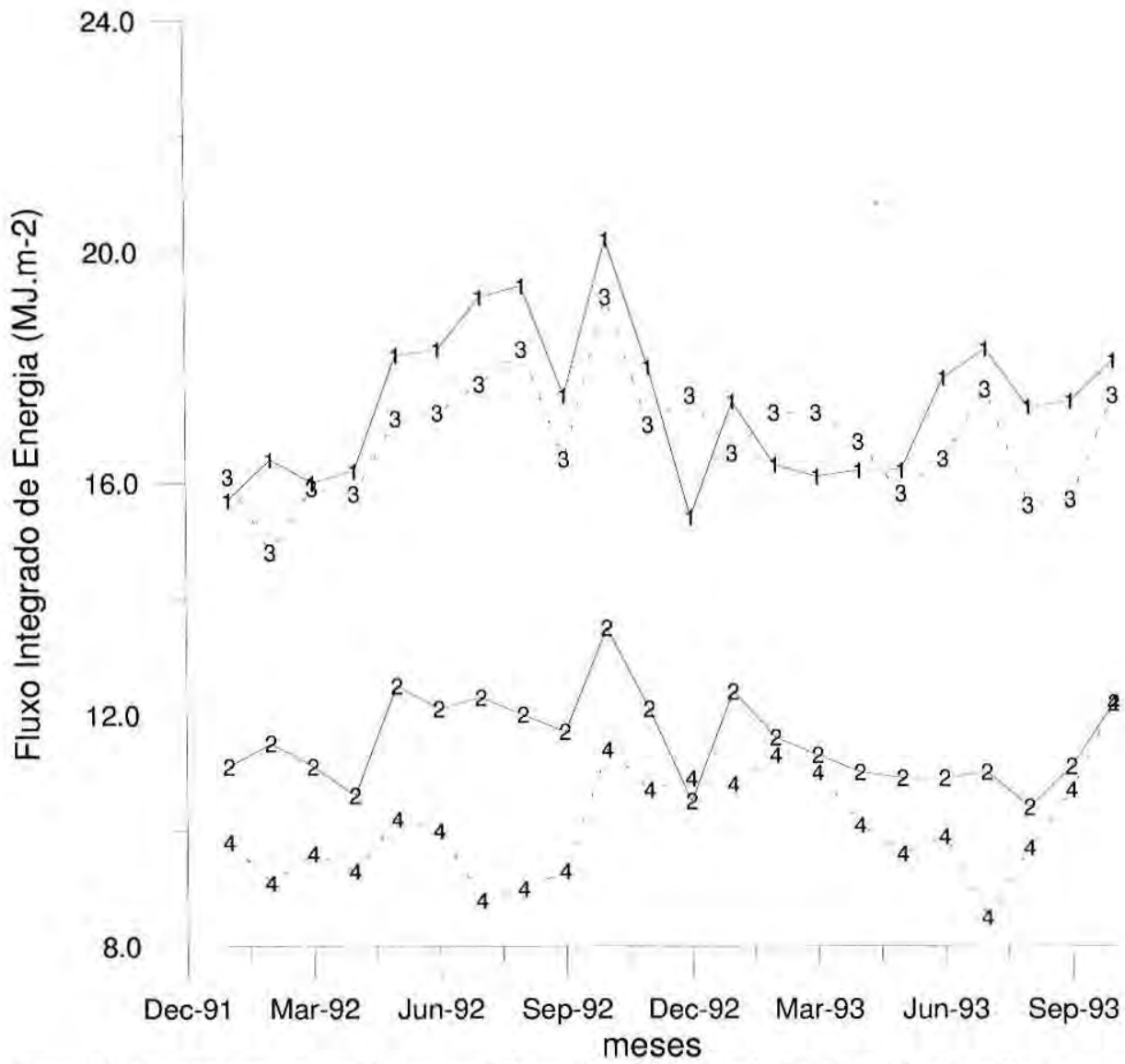

Figura 2. Comportamento médio mensal da radiação solar global e do saldo de radiação, no sitio de Ji-Paraná - RO, nas áreas de floresta ( 1 = radiação solar e 3=saldo de radiação) e pastagem ( 2 = radiação solar e $4=$ saldo de radiação), durante o período de Jan 92 até Out. 93 . ).

virtude da redução da radiação solar global no periodo, houve uma mudança na partição total de energia, sendo que a contribuição de ondas longas e a variação do albedo possibilitaram que não houvesse mudanças significativas no saldo de radiação. $\mathrm{O}$ aumento do saldo de radiação total diário médio na estação chuvosa, no sitio de pastagem, está associado a um aumento da umidade do solo no período chuvoso. Uma maior quantidade de água no solo provoca uma alteração na capacidade de absorção de energia pela vegetação, fenômeno que está relacionado com a mudança da cor da vegetação e consequentemente albedo (Culf et al., 1995).

\section{Velocidade do vento}

Pode-se observar que a velocidade do vento apresentou uma tendência de ventos mais intensos na estação seca, principalmente no sítio de floresta (Fig. 3). No sítio de pastagem este comportamento é mais facilmente distinguido no ano de 1992, onde o valor máximo da velocidade do vento ocorreu no mês de julho. Comparativamente, a velocidade do vento 


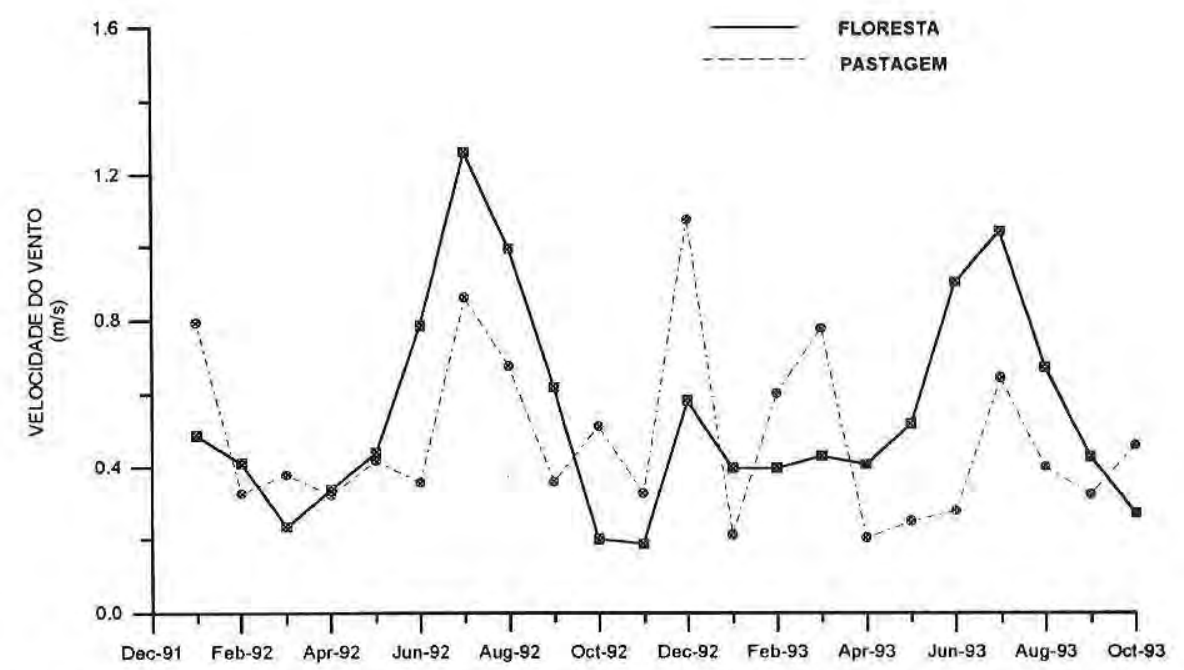

Figura 3. Comportamento médio mensal da velocidade do vento, no sítio de Ji-Paraná-RO, nas áreas de pastagem e floresta, durante o período de Jan. 92 até Out. 93.

foi maior no sítio de pastagem que no sítio de floresta $\left(0,4 \mathrm{~m} \cdot \mathrm{s}^{-1}\right)$, durante o periodo chuvoso $\left(0,5 \mathrm{~m} \cdot \mathrm{s}^{-1}\right)$. No período seco ocorreu o oposto, ou seja a velocidade do vento na floresta $\left(0,6 \mathrm{~m} \cdot \mathrm{s}^{-1}\right)$ apresentou valores maiores do que os registrados na pastagem $\left(0,5 \mathrm{~m} \cdot \mathrm{s}^{-1}\right)$. Um maior valor da velocidade do vento é favorável ao aumento da evapotranspiração, pois o processo de saida do vapor d'água é facilitado. Desta forma, o comportamento sazonal da velocidade do vento, ou seja o maior valor desta variável na estação seca, contribuiu para um maior valor da evapotranspiração neste periodo (item 3.1.3).

\section{Evapotranspiração}

O comportamento diário da evapotranspiração é apresentado na Figura 4. A evapotranspiração da floresta foi, em média, 1,0 mm.dia ${ }^{-1}$ maior que a da pastagem, no período de análise: enquanto a evapotranspiração média para a floresta foi $4,1 \mathrm{~mm} \cdot \mathrm{dia}^{-1}$, esse valor foi $3,1 \mathrm{~mm} \cdot \mathrm{dia}^{-1}$ para a pastagem. No período seco, a evapotranspiração média foi 4,5 mm.dia ${ }^{-1}$ para a floresta e 3,4 mm.dia 1 para a pastagem. No periodo chuvoso, a evapotranspiração média foi $3,6 \mathrm{~mm} \cdot \mathrm{dia}^{-1}$ para a floresta e 2,7 mm.dia ${ }^{-1}$ para a pastagem. O maior valor da evapotranspiração na floresta foi influenciado pela maior energia disponível para os processos evaporativos neste sítio. No sítio de pastagem, a diminuição da evapotranspiração no periodo chuvoso não pode ser explicada pela quantidade de energia disponivel. Foi observado um maior valor do saldo da radiação no período chuvoso em relação ao período seco e esta maior energia disponivel não acarretou um aumento da evapotranspiração. Este fato indica que o termo aerodinâmico foi o responsável pela diminuição da evapotranspiração no período. Foi observado que a velocidade do vento 


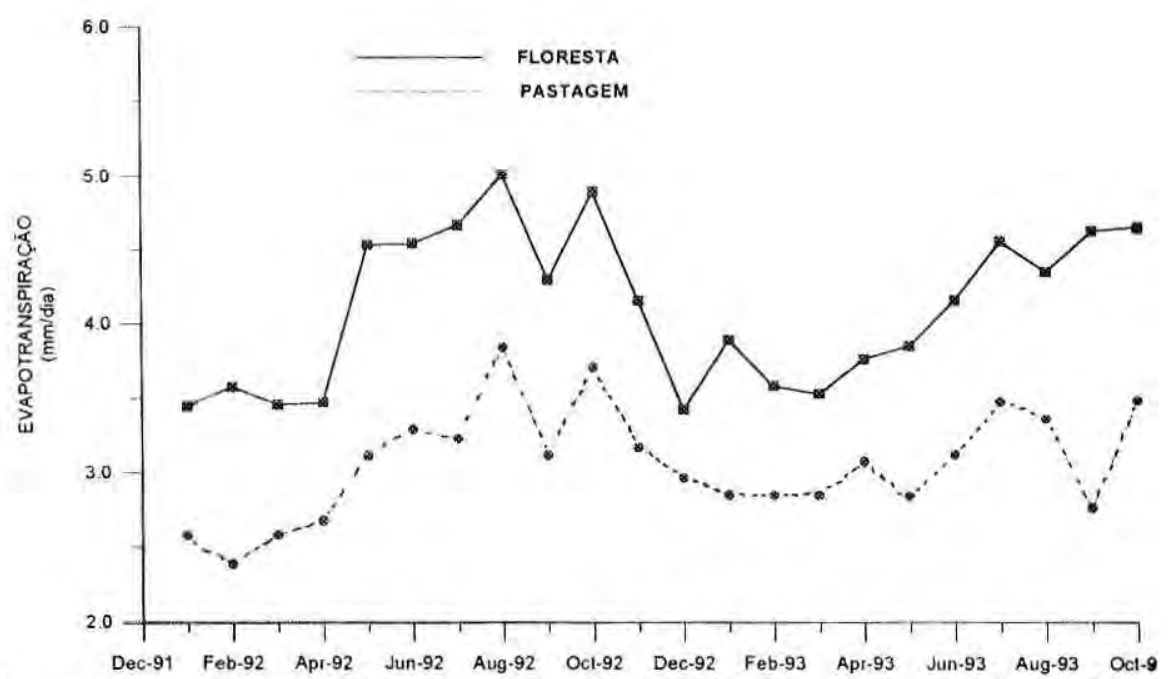

Figura 4. Comportamento médio mensal da evapotranspiração, no sítio de Ji-Paraná-RO, nas áreas de pastagem e floresta, durante o período de Jan. 92 até Out. 93.

foi menor no período chuvoso, em ambos os sitios. Uma menor velocidade do vento implica numa maior resistência aerodinâmica e consequentemente uma menor evapotranspiração. No sítio de floresta também não houve aumento do saldo de radiação no periodo seco. Neste sitio, o maior valor da velocidade do vento no periodo seco também foi o fator responsável pela maior evapotranspiração, em relação à evapotranspiração da estação chuvosa.

\section{Temperatura do ar}

A temperatura do ar teve seu comportamento descrito na Figura 5. A temperatura do ar média no periodo foi $24,6^{\circ} \mathrm{C}$ na floresta e $24,1^{\circ} \mathrm{C}$ na pastagem. $\mathrm{O}$ maior valor registrado para a temperatura média diária na floresta está associado a uma menor amplitude térmica diária nesse sítio, caracterizado por temperaturas diurnas menores e temperaturas noturnas maiores, em relação à pastagem. No período seco, a temperatura média do ar foi $23,9^{\circ} \mathrm{C}$ na floresta e $23,0{ }^{\circ} \mathrm{C}$ na pastagem. No período chuvoso, a temperatura média do ar foi $24,5{ }^{\circ} \mathrm{C}$ na floresta e $24,3{ }^{\circ} \mathrm{C}$ na pastagem. Houve uma redução no valor médio da temperatura do ar no periodo seco em ambos os sítios. Este resultado é influenciado pela ocorrência de frentes frias na região (denominado localmente de friagens). Foi constatado a ocorrência de seis eventos deste tipo no ano de 1992 e nove no ano de 1993. Durante a ocorrência de friagens, a temperatura máxima diária pode ser $10^{\circ} \mathrm{C}$ mais baixa que a máxima temperatura no dia anterior ao evento (Fisch et al., 1997). De acordo com o mesmo autor, a temperatura pode demorar de 2 a 3 dias para retornar aos valores registrados antes da passagem da frente.

\section{Umidade específica}

Conforme pode ser observado na Figura 6, a umidade especifica foi 


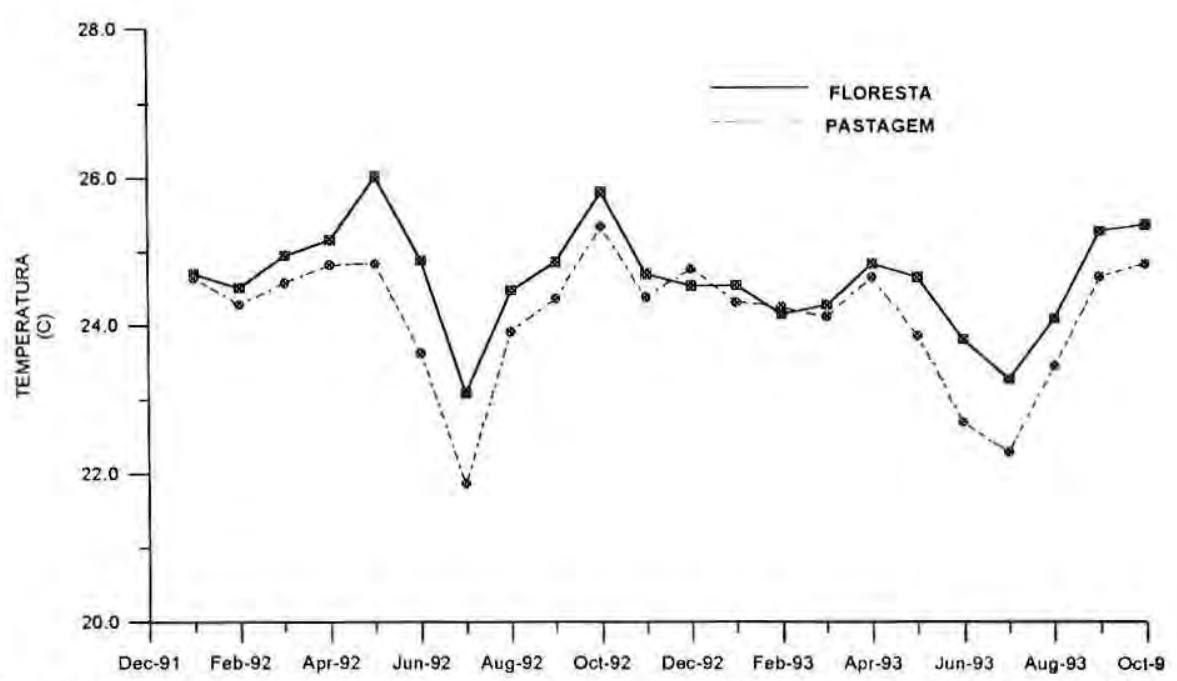

Figura 5. Comportamento médio mensal da temperatura do ar, no sítio de Ji-Paraná-RO, nas áreas de pastagem e floresta, durante o período de Jan. 92 até Out. 93.

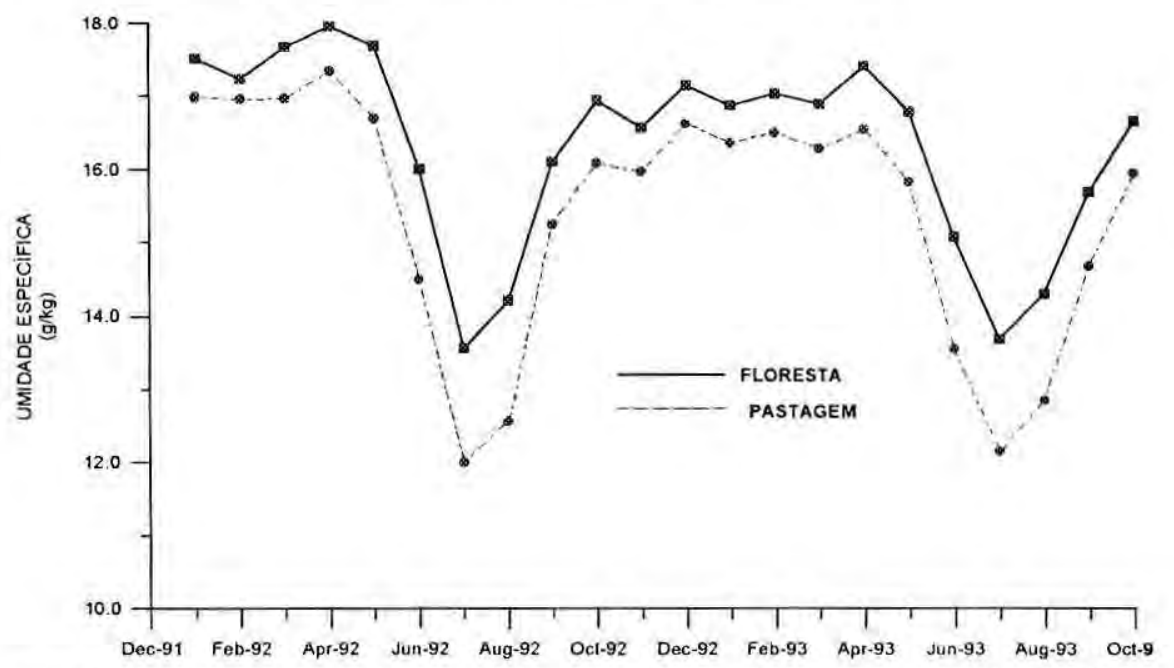

Figura 6. Comportamento médio mensal da umidade específica, no sítio de Ji-Paraná-RO, nas áreas de pastagem e floresta, durante o periodo de Jan. 92 até Out. 93.

sempre maior na floresta. A umidade chuvoso, a umidade especifica média foi específica da floresta foi, em média, $0,9 \quad 17,2 \mathrm{~g} \cdot \mathrm{kg}^{-1}$ na floresta e $16,7 \mathrm{~g} \cdot \mathrm{kg}^{-1}$ na g. $\mathrm{kg}^{-1}$ maior que a da pastagem, no pastagem. Portanto, houve um aumento período. Essa variável assumiu o valor da umidade específica no período médio de $16,3{\mathrm{~g} . \mathrm{kg}^{-1}}^{-1}$ na floresta e $15,4 \mathrm{~g} . \mathrm{kg}$ chuvoso, em ambos os sítios, resultado ${ }^{1}$ na pastagem. No periodo seco, a umidade especifica média foi $14,5 \mathrm{~g} \cdot \mathrm{kg}^{-1}$ na floresta e $13,0 \mathrm{~g} \cdot \mathrm{kg}^{-1}$ na pastagem. No periodo de uma maior presença de vapor d'água no ar, associado a uma maior precipitação neste período. 


\section{Precipitação}

A precipitação nos dois sítios pode ser analisada da Figura 7. Foi observada uma maior precipitação total para a floresta, considerando-se o período total de dados: precipitação total de $2.897,4 \mathrm{~mm}$ na floresta e $2.615,7 \mathrm{~mm}$ na pastagem. Fisch et al. (1997) também observou, usando resultados de modelos climáticos, que ocorre uma redução na precipitação ao substituir-se floresta por pastagem. Ferreira da Costa et al. (1998) usando dados observacionais de precipitação de $\mathrm{Ji}$ Paraná para o período chuvoso entre 19931996, verificou que ocorre uma precipitação $28 \%$ maior na área de floresta em relação à pastagem. No período seco, a precipitação observada foi $116,6 \mathrm{~mm}$ na floresta e $145,8 \mathrm{~mm}$ na pastagem. No periodo chuvoso, a precipitação foi $1.501,5$ $\mathrm{mm}$ na floresta e 1.149,3 na pastagem. Pode-se observar na Figura 7 que a precipitação teve um comportamento sazonal bem definido. Os primeiros meses do ano (janeiro-fevereiro-março) foram caracterizados por uma uma maior precipitação, ao contrário dos meses de junho, julho e agosto.

\section{Balanço Hídrico}

Para a realização do balanço hídrico, utilizou-se do valor da precipitação medida pelas estações automáticas, sendo que os valores de evapotranspiração foram calculados através da equação de PenmannMonteith. Calculou-se a quantidade de água no solo e a partir destes dados foi determinada a variação da quantidade de água no solo durante um certo intervalo de tempo. Durante a análise utilizou-se intervalos de uma semana, sendo o tamanho destes periodos dependentes do intervalo de tempo decorrido entre duas medições da quantidade de água no solo, realizadas aproximadamente em bases semanais. Dividiu-se o perfil do solo em

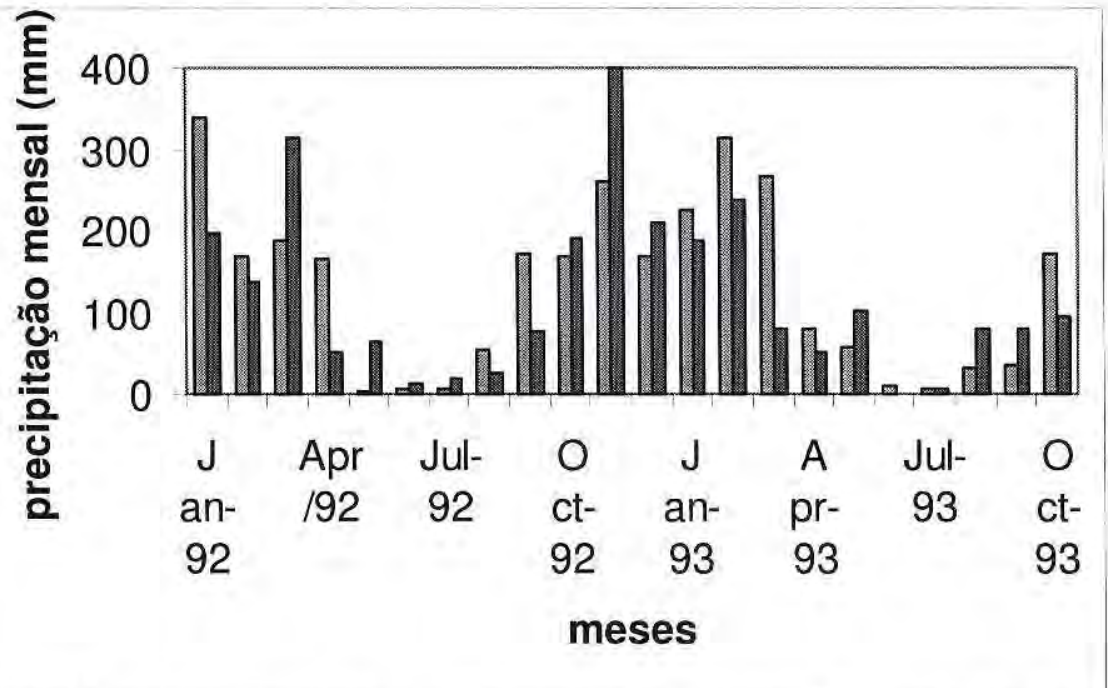

Figura 7. Comportamento médio mensal da precipitação, no sitio de Ji-Paraná-RO, nas áreas de pastagem e floresta, durante o período de Jan. 92 até Out. 93. 
duas sub-camadas: uma primeira camada mais superficial, variando de 0 a $2 \mathrm{~m}$ e uma outra camada mais profunda, estendendose de 2 a 3,6m de profundidade.

\section{Fazenda Nossa Senhora Aparecida}

Durante o período seco do ano de 1993, a camada de 2 a 3,6 m apresentou uma taxa de redução da quantidade de água em torno de 0,6 mm.dia ${ }^{-1}$ (Figura 8). Este valor está associado ao abaixamento do lençol freático. No final deste periodo, quando ocorreram algumas chuvas no

Reserva Jaru - floresta Ji-Paraná-RO início de setembro, essa taxa diminuiu para aproximadamente $0,17 \mathrm{~mm} \cdot \mathrm{dia}^{-1}$, um valor que indica aproximadamente a permeabilidade do solo. Este valor permaneceu praticamente constante até a chegada da estação úmida. A redução do valor da taxa de diminuição da quantidade de água no final da estação seca está associado ao reumedecimento do solo, com as primeiras chuvas de setembro, $o$ que fez com que as raizes existentes nesta camada parassem de extrair água da camada inferior do solo. No final de julho e começo de agosto de 1993, o

camada de 0 a $2 \mathrm{~m}$

camada de 2 a $3.6 \mathrm{~m}$

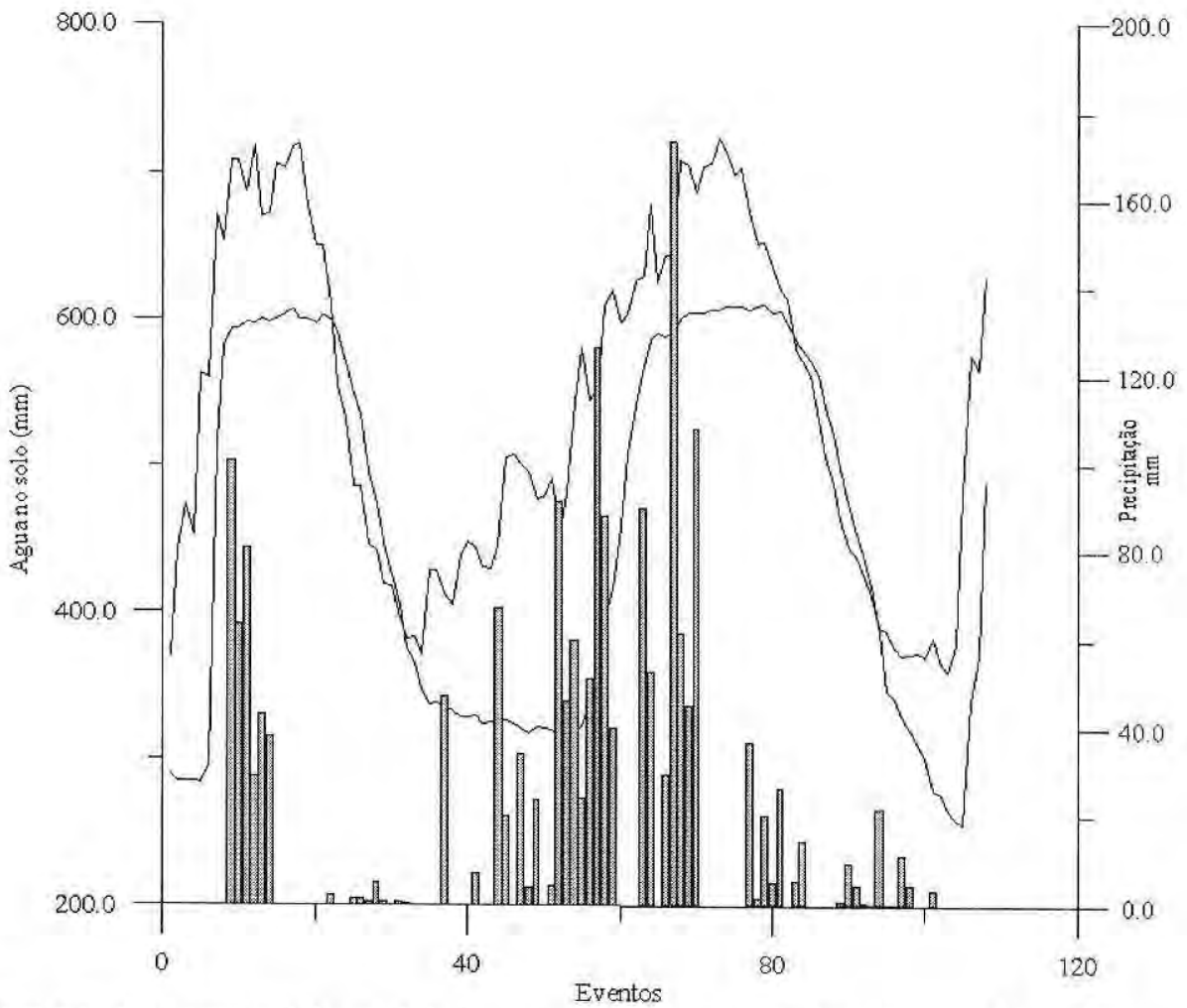

Figura 8. Série temporal da umidade de água no solo e precipitação da Fazenda Nossa Senhora Aparecida. Valores medidos em intervalo semanal. 
valor do resíduo $\mathrm{R}$ do balanço foi em média 2,0 mm.dia ${ }^{-1}$, indicando que ocorreu uma extração de água pelas raizes existentes na camada superior. Hodnett et al. (1996) obteve para o período de duas semanas no final de julho e início de agosto de 1993 o valor de $1,8 \mathrm{~mm} \cdot \mathrm{dia}^{-1}$ para a taxa de absorção de água pela camada superior. A Tabela 1 resume os valores médios do residuo $\mathrm{R}$, durante os diversos periodos de análise. Observa-se que no período chuvoso, em ambos os anos, o valor do resíduo foi positivo. Esse resultado está associado à ocorrência de escoamento superficial e de uma drenagem. na parte inferior da camada.

Observa-se ainda na Figura 8 que a camada 2,0 - 3,6 $\mathrm{m}$ apresenta uma menor diferença entre o valor de pico e o valor de mínimo da quantidade de água no solo. Outra observação advinda da mesma Figura é a rápida resposta da camada superior do solo à ocorrência da chuva, como pode ser constatado pela inclinação da curva pontilhada quando as primeiras chuvas são registradas. Esse resultado está associado à subida do nivel do lençol freático que saturou a camada inferior do solo, com o início da estação úmida. A Tabela 2 indica os valores de máximo e de mínimo da quantidade de água no solo, nas duas camadas estabelecidas para a análise.

\section{Reserva Jaru}

A peculiaridade deste sítio consiste no lençol freático estar localizado muito próximo à superficie. No período úmido, a camada 2,0-3,6 m chega a atingir a saturação, o que implica numa taxa de variação da quantidade de água no solo de aproximadamente zero.

Da mesma forma que no sítio de pastagem, observa-se no período seco um valor negativo do resíduo do balanço, o que está associado a uma extração, por parte das raizes da camada superior, da água localizada na sub-camada inferior do solo (Tab. 1).

Tabela 1. Valores médios do Resíduo do balanço hidrico para a Fazenda N.S Aparecida (NSAP) e Reserva Jaru (RJ), Valores em mm.dia'.

\begin{tabular}{lcccc}
\hline Ano & \multicolumn{2}{c}{1992} & \multicolumn{2}{c}{1993} \\
Periodo & Chuvoso & Seco & Chuvoso & Seco \\
\hline NSAP & $+9,1$ & $-1,3$ & $+5,0$ & $-2,0$ \\
RJ & $+5,1$ & $-3,0$ & $+6,0$ & $-2,5$ \\
\hline
\end{tabular}

Tabela 2. Valores da quantidade de água (S) no solo para a Fazenda N.S. Aparecida (NSAP) e Reserva Jaru (RJ). Valores em $\mathrm{mm}$.

\begin{tabular}{lcccc}
\hline Ano & 1992 & 1993 & & \\
água no solo NSAP & Mínimo & Máximo & Mínimo & Máximo \\
\hline Camada 0-2 m & 465,0 & 722,0 & 440,0 & 690,0 \\
Camada 2-3.6 m & 482,0 & 657,0 & 454,0 & 603,0 \\
água no solo RJ & Mínimo & Máximo & Mínimo & Máximo \\
\hline Camada 0-2 m & 370,9 & 719,5 & 358,9 & 723,3 \\
Camada 2-3.6 m & 315,0 & 606,4 & 255,0 & 609,2 \\
\hline
\end{tabular}




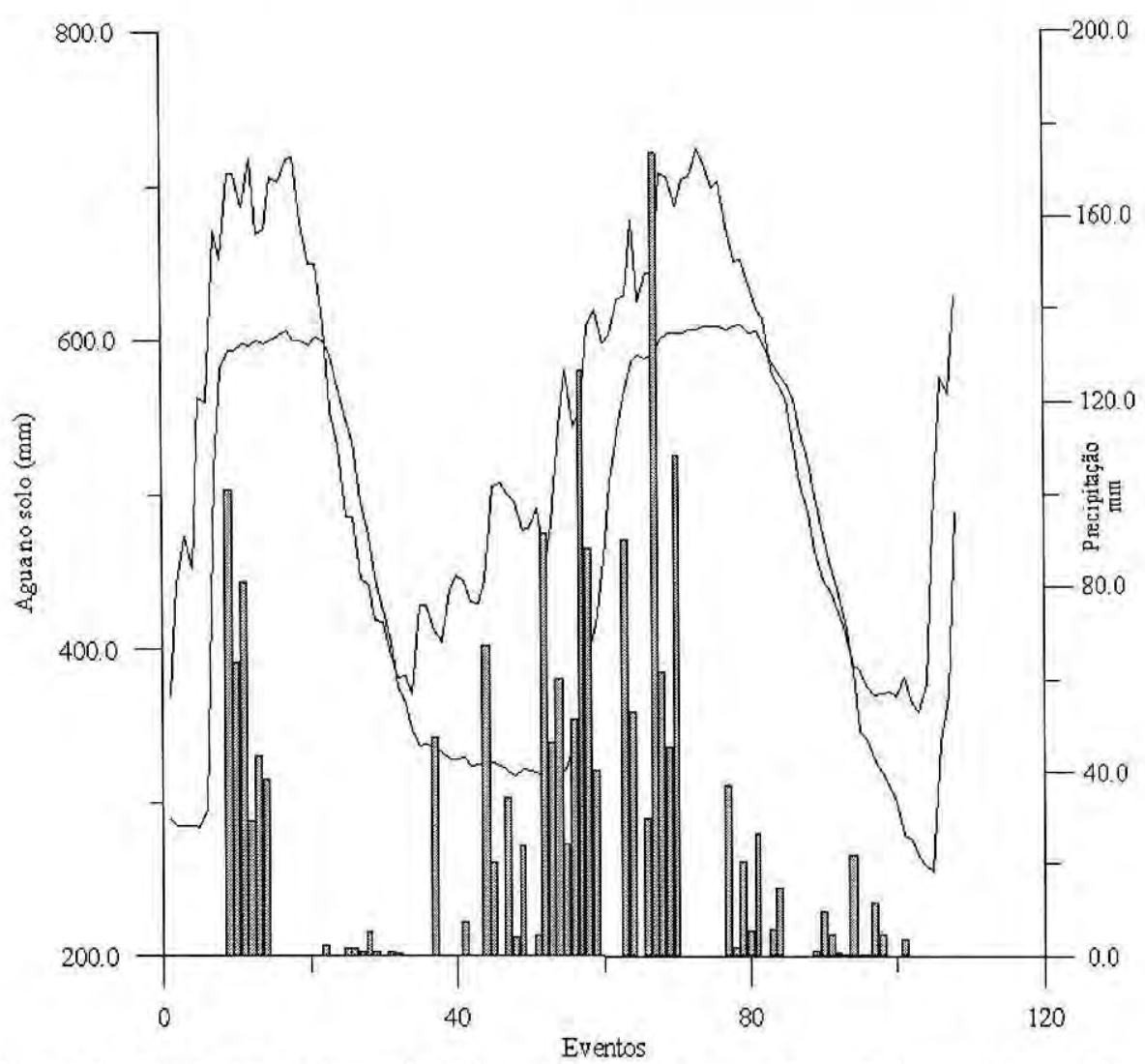

Figura 9. Série temporal da umidade de água no solo e precipitação da Reserva Jaru. Valores medidos em intervalo semanal.

Os valores deste resíduo neste período são, em valor absoluto, superiores aos valores registrados na pastagem, o que pode ser justificado pela maior quantidade de raizes profundas no sítio de floresta (Tab. 2). Segundo Nepstad et al. (1994) a floresta da Amazônia possui um sistema radicular que chega a atingir profunididades de até $10 \mathrm{~m}$.

\section{CONCLUSÕES}

Este trabalho realiza uma análise global das modificações microclimáticas e do balanço hídrico devido ao desmatamento na Amazônia, enfocando o caso de 2 sitios experimentais em Rondônia. A evapotranspiração calculada para a floresta foi, em média, 1,0 mm.dia' maior que a calculada para a pastagem. Isto corresponde a uma evapotranspiração $24 \%$ menor na área desmatada. Portanto, a substituição da vegetação de floresta por pastagem provocou uma redução no valor da evapotranspiração, considerando-se o período e região analisada. A precipitação total na pastagem foi $281,7 \mathrm{~mm}$ menor 
que na área de floresta, representando um decréscimo de $10 \%$. A temperatura do ar média na região foi maior na floresta. Este resultado está relacionado com uma maior amplitude térmica registrada na pastagem. Os maiores valores do saldo da radiação solar para a floresta propiciaram uma maior quantidade de energia disponivel e portanto taxas maiores de evapotranspiração. Em média, o saldo de radiação foi maior $1,7 \mathrm{MJ} . \mathrm{m}^{-2}$ dia na floresta, o que equivale a uma disponibilidade de energia para a evapotranspiração $17 \%$ maior na floresta. A velocidade do vento apresentou maiores valores para a floresta, facilitando a remoção do vapor d'água das proximidades da superficie e, consequentemente, a evapotranspiração.

Observa-se um maior valor médio absoluto do resíduo do balanço hídrico, durante o período seco, para o sítio de floresta. Este resultado indica uma maior capacidade da vegetação de floresta de suprir sua necessidade de água durante o período seco, o que está associada a uma maior profundidade das raízes permitindo a aborção de água em camadas mais profundas. A maior disponibilidade de água na vegetação de floresta durante estação seca é um dos fatores que favorecem uma maior evapotranspiração desta vegetação durante este período. Observa-se que os valores máximos de quantidade de água no solo são similares nos sítios de floresta e pastagem durante a estação chuvosa (ao redor de $720 \mathrm{~mm}$ de água na camada superficial), sendo que, durante a estação seca, a pastagem apresenta valores maiores de água no solo, pois as plantas não conseguem extrair a àgua como no caso de florestas.

\section{AGRADECIMENTOS}

O autor F.S. Maia Alves agradece à Fundação de Amparo à Pesquisa do Estado de São Paulo pela bolsa de iniciação cientifica (96/01950-5) que incentivou a realização deste trabalho. O Dr. G. Fisch agradece ao $\mathrm{CNPq}$ pela concessão da bolsa de produtividade em pesquisa do $\mathrm{CNPq}$ (300564/96-2). Este trabalho foi parte do Trabalho de Conclusão de curso de Engenharia de Infra-Estrutura do CTA/ ITA, desenvolvido por F. S. Maia Alves e apresentado em Dezembro de 1997. Este trabalho foi parcialmente financiado pelo Projeto PPD-G7 intitulado Balanço de Energia, Vapor D'água e $\mathrm{CO} 2$ em áreas de floresta tropical na Amazônia Central -95/0966.

\section{Bibliografia citada}

Culf, A. D.; Fisch, G.; Hodnett, M. G. 1995. The albedo of Amazonian forest and ranchland. Journal of Climate, 8(6):1544-1554

Ferreira da Costa, R.; Feitosa, J. R. P.; Fisch, G.; Souza, S. S.; Nobre, C. A. 1998. Variabilidade diária da precipitação em Regiòes de Floresta e Pastagem na Amazônia. Acta Amazonica, 28(4):395-408

Feitosa, J.R.P.; Ferreira da Costa, R.; Fisch, G.; Souza, S.S.; Nobre, C.A. 1998. Radiação solar global em árcas de floresta e pastagem na Amazônia. Revista Brasileira de Agrometeorologia, 6(1): 1-7, 1998

Fisch, G.; Lean, J.; Wright, I. R.; Nobre, C. A. 1997. Simulações climáticas do efeito do desmatamento na região Amazônica: estudo de um caso em Rondônia. Revista Brasileira de Meteorologia, 12(1):33-48

Hodnett, M. G.; Oyama, M. D.; Tomasella, J. 1996. Comparisons of long term soil water storage behaviour under pasture and forest in three areas of Amazonia. In: Gash, 
J.H.C.; Nobre, C.A.; Roberts, J.M; Victoria, R.L. (Eds). Amazonian Deforestation and Climate. John Wiley, Chicester-UK, p.57-77.

Moore, C. J.; Fisch, G. 1986. Estimating heat storage in Amazonian tropical forest. Agricultural and Forest Meteorology, 38(1-3):147-169

Nepstad, D. C.; Carvalho, C. R.; Davidson, E. A.; Jipp, P. H.; Lefrebvre, P. A.; Negreiros, G. H.; Da Silva, E. D.; Stone, T. A.; Trumbose, S. E.; Vieira, S. 1994. The role of deep roots in the hydrological ans carbon cycles of Amazonian forest and pastures. Nature, 372(6507):666-669

Nobre, C. A.; Sellers, P. J.; Shukla, J. 1991. Amazonian deforestation and regional climate change. Journal of Climate, 4(10):957-988
Shuttleworth, J. W.; Gash, J. H. C.; Lloyd, C. R.; Moore, C. J.; Roberts, J. M.; Marques, A. O. F. de; Fisch, G.; Silva, V. P. R. de; Ribeiro, M. N. G.; Molion, L. C. B.; Sa, L. D. A.; Cabral, O. M. R.; Patel, S. R.; Moraes, J. C. 1984. Eddy correlation for Amazonian Forest. Quarterly Journal of the Royal Meteorological Society, 110(466):1143-1162

Wright, I.R.; Manzi, A.O; Da Rocha, H.R. 1996. Modelling surface conductance for Amazonian pasture and forest. In: Gash, J.H.C.; Nobre, C.A.; Roberts, J.M.; Victoria, R.L. (Eds). Amazonian Deforestation and Climate. John Wiley, Chicester-UK, p.437-458. 